\title{
BMJ Open Green shoots of recovery: a realist evaluation of a team to support change in general practice
}

\author{
Maggie Bartlett, Ruth Basten, Robert K McKinley
}

To cite: Bartlett M, Basten R, McKinley RK. Green shoots of recovery: a realist evaluation of a team to support change in general practice. BMJ Open 2017;7: e014165. doi:10.1136/ bmjopen-2016-014165

- Prepublication history for this paper is available online. To view these files please visit the journal online (http://dx.doi.org/10.1136/ bmjopen-2016-014165).

Received 7 September 2016 Revised 13 December 2016 Accepted 20 December 2016

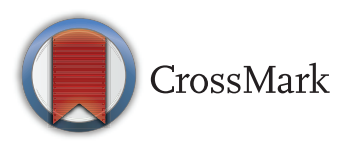

Keele School of Medicine, Keele University, Keele, UK

Correspondence to Dr Maggie Bartlett; m.h.bartlett@keele.ac.uk

\section{ABSTRACT}

Objective: A multidisciplinary support team for general practice was established in April 2014 by a local National Health Service (NHS) England management team. This work evaluates the team's effectiveness in supporting and promoting change in its first 2 years, using realist methodology.

Setting: Primary care in one area of England.

Participants: Semistructured interviews were conducted with staff from 14 practices, 3 key senior NHS England personnel and 5 members of the support team. Sampling of practice staff was purposive to include representatives from relevant professional groups.

Intervention: The team worked with practices to identify areas for change, construct action plans and implement them. While there was no specified timescale for the team's work with practices, it was tailored to each.

Primary and secondary outcome measures: In realist evaluations, outcomes are contingent on mechanisms acting in contexts, and both an understanding of how an intervention leads to change in a socially constructed system and the resultant changes are outcomes.

Results: The principal positive mechanisms leading to change were the support team's expertise and its relationships with practice staff. The 'external view' provided by the team via its corroborative and normalising effects was an important mechanism for increasing morale in some practice contexts. A powerful negative mechanism was related to perceptions of 'being seen as a failing practice' which included expressions of 'shame'. Outcomes for practices as perceived by their staff were better communication, improvements in patients' access to appointments resulting from better clinical and managerial skill mix, and improvements in workload management.

Conclusions: The support team promoted change within practices leading to signs of the 'green shoots of recovery' within the time frame of the evaluation. Such interventions need to be tailored and responsive to practices' needs. The team's expertise and relationships between team members and practice staff are central to success.

\section{Strengths and limitations of this study}

- Realist methodology is recognised as appropriate and relevant for evaluating complex interventions in healthcare environments. Recently published reporting standards informed its use in this work.

- All practices which engaged with the team in its first 2 years were involved in the evaluation and a range of staff were interviewed, not just those in leadership roles.

- Practices which did not engage at all with the team also declined to participate in the evaluation; the views of this important group of practices are therefore not represented.

- The study is embedded in the context of a highly inspected, highly regulated service: generalisability to less heavily managed systems cannot be assumed.

- Two of the evaluators work as general practitioners in the medical community in which the team works and this may have led to bias; however, their practice of reflexivity reduces the impact of this.

\section{INTRODUCTION}

Universal access to high-quality primary care is an important driver of the health of a population. ${ }^{1}$ Although the UK offers universal access to primary care, there are substantial differences in the quality of care provided by its general practices. ${ }^{2}$ In the UK, general practice quality is measured and monitored using a range of quality indicators $^{3-7}$ and inspections by the Care Quality Commission (CQC), ${ }^{8} 9$ a regulatory body which has a statutory responsibility to ensure that health and social care in the UK is safe and effective. The quality data and the CQC's reports are publicly available and failures to reach these standards consequently become public knowledge; this "naming and shaming' has become part of the process of improving accountability within the UK's National Health Service (NHS). ${ }^{10} 11$ 
While staff are a key determinant of the quality of care provision, a 2006 literature review ${ }^{12}$ regarding team effectiveness in healthcare concluded that there is no single model of an 'effective team'; team composition and function need to be tailored to their purpose. No clear direction could be given for the creation or maintenance of a 'high-functioning team'. Nevertheless, team leadership is important: Aranzamendez et $a l^{13}$ concluded that 'psychological safety' for teams arising from the characteristics of leaders has a high impact on healthcare quality. Other literature focuses on the effectiveness of teams, facilitators or learning programmes which aim to promote specific quality improvement initiatives ${ }^{14-16}$ rather than general improvements in practice function. There is some evidence from Canada that such initiatives improve communication, collaboration and leadership. ${ }^{16}$ However, Dean et $a l^{17}$ reported primary care teams' concerns about wasted effort and resources being barriers to their adoption of quality improvement activities.

In 2014, an NHS England Local Area Team (the management 'layer' of the NHS which then had responsibility for commissioning primary care medical services) established and funded a 'Supporting Change in General Practice' team (the SCGP team). The SCGP team's stated aim is to 'improve the quality of working life for practice staff, achieve sustainable positive change and improve care for patients in the locality', a population of 1.4 million people which was served by $\sim 200$ general practices. It was not established specifically to support practices to prepare for or remediate after a CQC inspection, ${ }^{8}$ but for any practice which wanted or needed help to change. The SCGP team has five members, all of whom are employed solely to undertake this work and all have relevant experience in the NHS: a general practitioner (GP), a practice manager, a nurse, an administrator and an analyst. Practices do not contribute to its costs. The SCGP team does not have a regulatory role and does not impose solutions or sanctions on practices; engagement is voluntary even in the situation of a practice having failed a CQC inspection. The SCGP team collates data from a variety of sources during a 'scoping' stage with the practices. These data inform discussions between the SCGP team and practice staff in an action planning stage, which is followed by the implementation of the action plan, in which the SCGP team may or may not be involved and for which it maintains an 'open door' policy, meaning that there is no point at which it formally ends its relationship with a practice. Clinical backfill is available, provided by the team's GP.

Little has been published about support teams for general practices. The only similar intervention of which we are aware is the UK-based Royal College of General Practitioners (RCGP) pilot ${ }^{18}$ in which a team provides support for practices in 'special measures' after CQC inspections. ${ }^{8}$ There are important differences in the way they operate; for example, the RCGP team has 'two or three advisors' and practices are expected to contribute to its costs. ${ }^{18}$ No evaluation of this team has as yet been published.

The Keele School of Medicine was commissioned by NHS England to evaluate the team's effectiveness over a 2-year period (April 2014 to March 2016).

\section{METHODS}

We used realist methodology ${ }^{19}{ }^{20}$ which seeks to explain how, why and when an intervention leads to change by considering configurations of contexts, mechanisms and outcomes $(\mathrm{CMO}) .{ }^{19} \mathrm{~A}$ realist evaluation is a cyclical process of making and testing hypotheses with the aim of specifying CMO configurations in which change has occurred. It is increasingly used for the evaluation of complex interventions in socially constructed settings such as healthcare. ${ }^{19} 20$

We considered using a 'quasi-experimental' quantitative methodology $y^{20}$ involving NHS performance indicators. ${ }^{3-5}$ However, the way these performance indicators are applied and used in the NHS is not stable and they are no longer reliable measures of change. ${ }^{21}{ }^{22}$ We also considered quantitative measures of team function ${ }^{23}$ but the likelihood of abreactions by practice teams early in the process of change ${ }^{24} 25$ meant that these were unlikely to be reliable indicators of change within the timescale of the evaluation.

We describe one cycle of the realist evaluation process using the RAMESES II reporting standards. ${ }^{20}$

- Interviews with key personnel from NHS England, the members of the SCGP team, and practice staff to inform the development of a conceptual foundation or programme theory ${ }^{19}{ }^{20}$ for the intervention.

- Data analysis from a realist perspective ${ }^{1920}$ to specify contexts, mechanisms and outcomes. We grouped mechanisms into 'resource' and 'reasoning' mechanisms, as willingness and ability to change depends on the resources available and the reasoning behind the choices people make. ${ }^{19}$

- Further interviews with practice staff in order to test hypotheses about the CMO configurations which resulted in change.

- Development of a programme specification. ${ }^{19}$

\section{The interviews}

We used purposive sampling for NHS England staff and SCGP team members, and stratified sampling for practice staff. For practice staff, we aimed for a representative variety of professional groups in the practices (GP principals and sessional doctors, nurses, healthcare assistants, managers, administrators and receptionists). All interviews were semistructured, audio-recorded and transcribed with participants' consent. The questions were open and invited comment on experiences and perceptions. 
Initial interviews with practice staff took place after the SCGP team's scoping stage and follow-up interviews several months later when it was conceivable that change would be identifiable. Their purpose was to test hypotheses, thus refining the programme theory. ${ }^{19}{ }^{20}$ All the SCGP team members were interviewed throughout the evaluation period, and key people from NHS England were interviewed once.

The data were analysed thematically by two researchers independently and then several iterations of discussion organised and refined the themes in CMO configurations.

Descriptive data relating to the practices were obtained from the SCGP team.

\section{Ethics}

According to the NHS research ethics decision tool, ${ }^{26}$ this work is an evaluation rather than research, and approval from an NHS Research Ethics Committee was not required. The project was discussed with the Primary Care Research and Development Manager of the National Institute for Health Research (NIHR) Clinical Research Network (West Midlands, UK), who gave permission for it to proceed on 4 April 2014. It was discussed with Keele University's Research Governance Officer on 19 March 2014; approval of the University's Ethics Review Panel was not required.

The work was carried out with the intention of, as far as possible, maintaining the confidentiality of practices and individuals.

\section{RESULTS}

We report on data relating to 14 practices. Four practices had approached the SCGP team, one because staff were concerned about preparing for a CQC inspection. ${ }^{8} 9$ Nine were identified and approached by the SCGP team as a result of being outliers in performance data sets. One practice engaged with the team as a direct result of an unsatisfactory CQC inspection report.

Initial and follow-up interviews were conducted for five practices. For the rest, for reasons of timing or staff agreement, only one set of interview data was obtained.

\section{The practices}

There were three rural practices (located in settlements of $<10000$ people) $)^{27}$ and 11 urban ones. The registered list sizes varied between 3000 and 15000 . The numbers of whole time equivalent (WTE) doctors ranged from 1.75 to 8.125 and the WTE:list size ratios from 1335 to 3050 (the mean for England in 2014 was 1678.) ${ }^{28}$

\section{Interviews with the SCGP and NHS England staff}

All the SCGP team members were interviewed individually twice (April 2014, January 2015) and as a group three times (June 2014, August 2015, February 2016).

Three key people from the local team of NHS England were interviewed: the Medical Director individually, and the Head of Primary Care and the Primary Care Lead together.

\section{Interviews with practice staff}

A total of 72 interviews were carried out with staff from 14 practices:

- 15 practice managers;

- 18 GP partners who 'led' their practice's work with the team;

- 6 other GP partners;

- 17 nurses;

- 6 receptionists;

- 8 administrators;

- 2 sessional GPs.

\section{Constructing a programme theory}

The SCGP team's purpose was consistently viewed as being to provide help and support for practices which were 'struggling' or 'vulnerable'. It was perceived by two NHS England staff as having a specific purpose in supporting practices to develop action plans as required by the CQC, ${ }^{8}{ }^{9}$ but this had not been originally given as a primary reason for establishing it. They had clear ideas about criteria for success, for example, patient survey data and other performance indicators, the focus being on outcomes for patients. The Medical Director (NHS England local team) reported that he had 'no clear set criteria for success', but that the team's work would lead to "visible green shoots of recovery, maybe manpower, maybe patient satisfaction, maybe something else..." and that it would be specific to each practice. His view was that "the NHS is changing too quickly to rely on some of the indicators such as the Quality and Outcomes Framework $]^{3}$ they are no longer a stable measure...".

The SCGP team's own criteria for success changed over the 2 years; from initially being focused on outcomes for patients, by February 2016 the emphasis was on better communication within practice teams, increased morale, and sustainability for the practices and the individuals within them. The team members developed a perception that these might take time to achieve. The SCGP team itself did not perceive the CQC work as ever being 'the majority' of its workload.

Practice staff perceived that they needed to change and were hoping that they would perform better as a result of the work. They speculated about benefits to themselves in terms of better morale and a more managed workload, and concomitant benefits for patients.

The analysis of the interviews, with the incorporation of concepts described in the King's Fund's 'Exploring the CQC's Well-led Domain', ${ }^{29}$ led to the development of a programme theory:

"When practices are identified as performing poorly, work with a multi-disciplinary team to help them to identify areas and strategies for improvement and then support them to implement these strategies, may lead to better practice performance and sustainability for 
individuals and practices. As the purpose of general practices is to provide good quality care for patients, better performance will lead to better outcomes for patients in the future." (see figure 1).

\section{Contexts, mechanisms and outcomes}

\section{Contexts}

All practices were operating in the contexts of the NHS in England and their local medical communities. Each practice had its own context of patient demographics, staffing structures, service provision and challenges. Most staff were working in a context of perceived suboptimal management and leadership, and many with suboptimal clinical team skill mix and staff deployment, particularly in their nursing teams. A significant aspect of context was the route to engagement with the team; some had actively asked for help while some had accepted it willingly or reluctantly when it was offered to them. Some felt that they were individually or collectively 'at breaking point' and that help was essential. Some expressed concern about why they had been identified as needing help and some that the reason they were offered it was never made clear.

The context of the NHS in England was perceived by all as challenging; practice staff described themselves as being on a 'hamster wheel', the work being 'pressured' and 'frantic'. The team described a set of problems common to all practices, including workload, staff recruitment, financial viability and personal sustainability.

\section{Mechanisms}

Identified mechanisms were grouped into 'resource' and 'reasoning' mechanisms, as willingness and ability to change depends on the resources available and the reasoning behind the choices people make (table 1). ${ }^{19} 20^{\circ}$

The most powerful resource mechanism was the practical expertise of the SCGP team, particularly of its manager, which was mediated by the nature of the relationships between practice staff and team members. This practical expertise included knowledge of human resources and business management, NHS processes, professional regulation and clinical skill development.

The SCGP team described an action plan, owned and constructed by the practice staff, as being 'primary'; however, from the practice staff's perspectives, the value was variable and dependent on context; those practices concerned about $\mathrm{CQC}^{8}{ }^{9}$ inspections placed more value on it and there was evidence that they used it more in their implementation of change, particularly the practice in special measures after a CQC inspection. For others, action plans were more evolutionary and more fluidly used, or not used at all.

The provision of clinical backfill was perceived as a positive resource by some practice staff in that it gave doctors time away from clinical duties to take part in discussions and developmental work, but it was perceived by some as being part of the inspection and giving the SCGP team an opportunity to look at doctors' clinical practice and find out what the patients thought about the doctors, and therefore caused some anxiety.

The most powerful reasoning mechanism was the 'external view' provided by the team and its corroborative and normalising effects. In some practice contexts, this corroboration was perceived negatively by practice staff; they felt that the team's work added nothing new to their knowledge about the difficulties they were facing. Others expressed relief that no unexpected problems were found by the team.
Figure 1 The programme theory.

Definitions: CQC, Care Quality Commission.

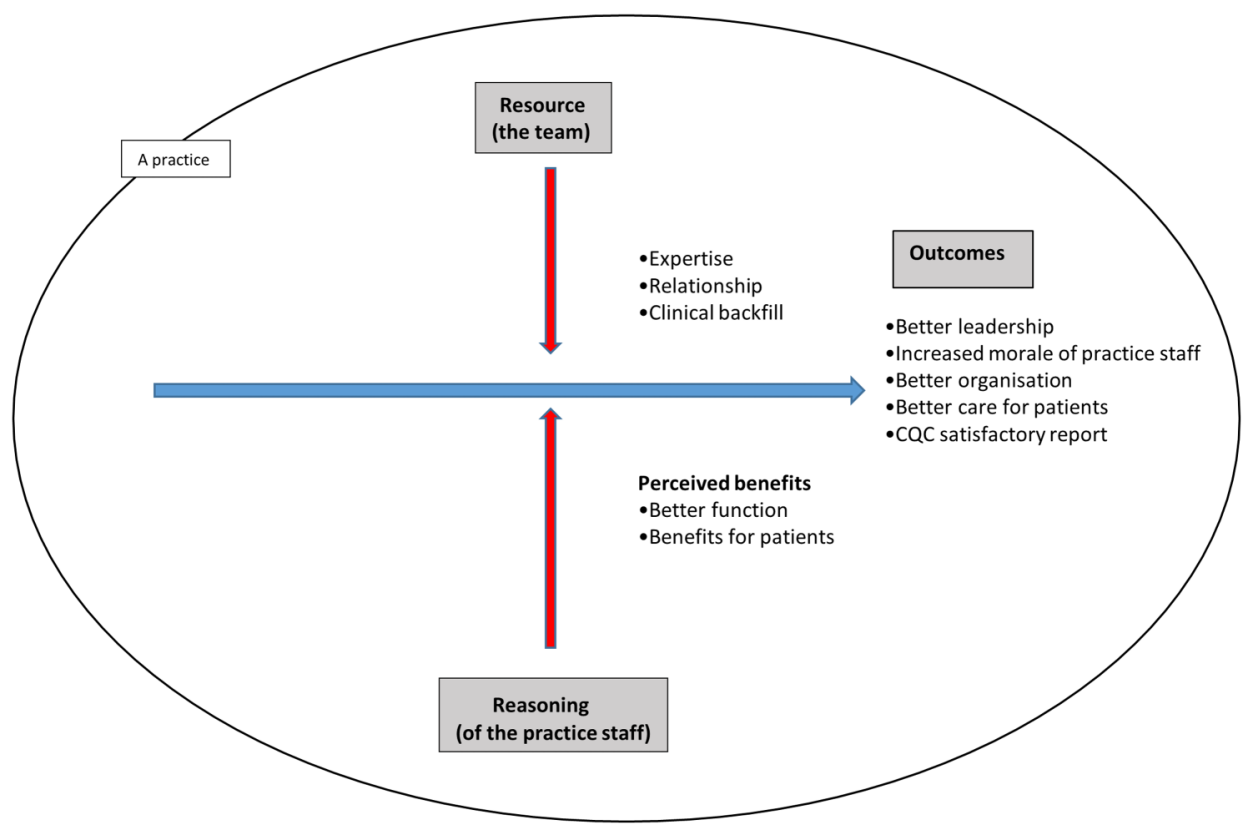


Table 1 The mechanisms

\section{Mechanism}

Resource-positive

Relationship

Expertise

Action planning

Clinical backfill

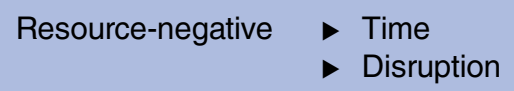

Relationship

Clinical backfill

Action planning

\section{Quotes regarding mechanisms}

"they've not directed us... and brilliantly have not just come and told us well, you need extra doctors but actually - what have you got, how can you work with it?" GP partner practice $\mathrm{K}$

"It was one of those very rare opportunities where we've had people come in from outside who are here to offer us support and look at us in a way that I felt wasn't gonna be judgmental." GP partner practice G

"They've been quite sensitive to the pressures that are there...they've not impacted greatly on our day to day practice...they've been very flexible... it hasn't felt very intrusive." GP partner practice M

"They weren't the inspectorate from hell." GP partner practice E

"...she understood where we were coming from and all the different areas we... sort of got issues with...that was good." Nurse practice $\mathrm{H}$

"Some of their suggestions have been very helpful, particularly trying to lighten our load with paperwork and helping with some changes with the nursing team." GP partner 1 practice $C$

"[the manager] was extremely helpful in looking over pitfalls in reception management and he helped us in interviews [to recruit new staff]." GP partner practice $\mathrm{E}$

"To get a report suddenly landing on your desk saying how terrible you are is one thing, but to get somebody coming in and saying well, we think you're terrible but we're going to try to help you-it's kind of a different process." Manager practice $\mathrm{H}$

“...the big advantage the team has got it that they've all been working in general practice and know how that is..." Manager practice $C$

"We sat down and we've had an action planning morning....and [we] invited [the manager on the Team] to come back...to say right, this is our action plan... which bits are you going to support us with?...he was very good...he's going to be coming back at the end of the month to arrange some other [aspects of the plan]." GP partner practice $C$

"The action plan has been ongoing from the minute they started really...it's in place and its working...it's about communication." Manager practice $L$

"I think the other thing that was quite useful was that [he] did a few clinics for us, so it released the doctors to do some of the work we needed to do..." Practice Manager $\mathrm{C}$

"the other thing that was quite useful was that [the team's GP] did a couple of afternoon surgeries here..." GP partner practice K

"There's always a bit of anxiety about how much extra work is all this going to create, you know, in an already frantic job..." Manager practice $C$

"I think we felt a bit- invaded is too strong a word, but I think sort of... we felt as if we had been taken over, rather than that we were in control of it." Manager practice $\mathrm{N}$

"[one of the team was talking] about other places [the team] was going, and because of my knowledge of the area, and sort of awareness, [the team member] referred specifically to a change that was going on which I could identify...I lost confidence in sharing or exploring ideas I had." GP partner practice $F$ "... it was like they'd got their own agenda whereas we'd got our agenda...' Manager practice $\mathrm{F}$

"When I had my interview... [we] had a conversation about personal experiences [with another organisation] and so forth and didn't feel a great deal of focus was on the practice to be honest... [the others] did tell me that they felt like they were being interviewed for a job... which I felt was a bit odd really." GP partner practice $\mathrm{D}$

"...a lot of talking went on and not much listening..." GP partner practice $C$ "[he did some clinical work]... and that got him an insight of the patient and what the patient thinks about us....he didn't find anything clinically wrong...' Practice manager practice $\mathrm{E}$

"the action plan, it seemed appropriate...I got the message, but actually I haven't referred back to it...I haven't actually shared it very much because it didn't have 
Table 1 Continued

\begin{tabular}{ll}
\hline Mechanism & \\
& \\
Reasoning-positive & Perceived benefits \\
& Function \\
& External View \\
& Corroborating \\
& Normalising \\
& Advocacy
\end{tabular}

\section{Quotes regarding mechanisms}

the challenge or the affirmation which I wanted." GP partner practice $F$

"we haven't referred back to it...I'm not sure if we did find it that useful...it was a massive long document..." GP partner 2 practice $C$

".... if we're a better run practice.... better team...you probably can't measure it, but l'm sure there will be benefits to the patients." GP partner practice K

"I wanted some help and guidance, an external sort of peer review...to make sure I wasn't completely off track." GP partner practice F

"it's good to have somebody look at the practice with a fresh pair of eyes and it's good to have feedback so that we can improve." Salaried GP practice H

"...you can become very insular and sometimes you can't see problems facing you and someone else coming in objectively can see what's going on and things you could improve..." Nurse practice $\mathrm{N}$

"it was nice to know that we weren't struggling in isolation, that everybody was dealing with the same problems, and that some of the changes we'd put in place were innovative and useful..." GP partner practice $J$

"...we felt better for them having come and told us we were doing well." GP partner practice $\mathrm{J}$

"I do think that they've really identified the key problems.... a third party's eyes have been useful...I think it just carries a bit more weight [in getting things changed]." Administrator practice M

"....its sort of like another voice to say what l'm actually able to do...to help me develop my role to its full potential..." Nurse practice $E$

Reasoning-negative Shame

"we asked why we were contacted, because we were given the impression it was to support failing practices and we didn't particularly think we were a failing practice, and they couldn't really give us an answer, and so that was a bit sort of disturbing..." Practice manager

"it was seen as we were picked on because we were a failing practice..." GP partner practice $\mathrm{C}$

"[someone] comes in and says oh yes, you're not doing very well so we want to come in and help you-you know that's a very different thing from me saying oh, can I have a bit of help please?" GP partner practice C

"[the staff needed to be] assured that it's not sinister...that they're not on trial in any way. It was hard to get the staff to understand that [the Team] were here to support what we were doing..." Practice manager practice B

"an email came...I thought maybe someone's picked up something wrong with our practice..." Practice manager practice $D$

"I think the [practice team] were a bit apprehensive-to think Oh God, are we in trouble...?" Receptionist practice $\mathrm{H}$

"...to be suddenly told yet again that you are failing... was sad really... when we think we're trying our hardest....we'd got the initial 'oh my God we're terrible again..." Practice manager practice $\mathrm{H}$

"...[we] felt very exposed and vulnerable [as a result of being contacted by the SCGP team]" GP practice C

Regulation/

inspection

"[some people] were completely freaked out by the idea that a team could come along and look at how you were working and felt that it was another CQC or Big Brother sort of thing...a sort of policing service." GP partner practice M

"...they were like a Big Brother coming in, checking, saying oh, oh you need to be reported to managers, chief whatever it is..." GP partner practice E ".... [people] were all saying we don't want them coming, I think they looking at it as an inspection process...they are being used by NHS England to go in to support practices that are failing.' Manager practice $M$

Mistrust "....we were a bit suspicious really, because we were going, well why are you contacting us?...we wanted to know what the whole thing was about... who referred us... we never did find that out..." GP senior partner practice $C$

Corroboration "we were just told when we had the feedback last week what we knew already...it was three days of practice time and then the feedback was a bit disappointing really." Practice manager practice $D$ 
The most prominent negative reasoning mechanism was a concern associated with engagement with the team, which was expressed most strongly by the practice managers; they were worried about being perceived in the local medical community as 'failing practices' if they were known to be working with the team. We interpreted this as an expression of shame.

Further negative reasoning mechanisms were the perceived generic nature of the intervention, and some negative aspects of the relationships between team members and practice staff which were related to issues of trust, both of individuals in the team and 'the NHS'.

\section{Outcomes}

Within the timescale of this evaluation, the principal outcomes perceived by the practice staff were better skill mix and deployment of clinicians improving access for patients, better workflow arising from better deployment of administrative staff, better communication within practice teams and increased morale (table 2). The fact

\section{Table 2 The outcomes}

\section{Group Quotes regarding outcomes}

The NHS England staff

“...[I have] no clear set criteria for success...[but] the team's work has led to visible green shoots of recovery, may be manpower, may be patient satisfaction, maybe something else..."

"... [the team are] able to take a practice, work with them very closely, help them prepare an action plan...not only bring the practice up to a level to get through the CQC inspection but to bring them up to a level that they are on a par with other practices."

"...to see a practice that has gone from absolute despair to a practice that's almost enjoying the process because they can see the benefits that they're starting to get from not working in total isolation."

The Supporting Change "the general feel of the place is a measure of success- smiling faces, relaxed, talking, light at end team of tunnel feeling and can see a way out...'

"[success is] going back to the practice to see how they're getting on-their morale was low and they weren't seeing their way out of this, and them saying we've had this crisis and this crisis and this is what we've done about it-solved it-and we have this crisis coming up and this is how we're planning to deal with it, and with a confidence on their face...real success in this case is the turnaround in morale, in this case that they're doing it themselves...but even better when they see these things as challenges but not crises, and just life-that's just what needs doing."

Practice staff "... [it was] very, very good for morale and I think if morale is lifted you work better, so yes, in that sense it was useful. GP partner practice $J$

'we've got a prescribing lead now...we've shared a lot of the work out...we've got a management partner..." GP partner 1 practice C

"it made us aware that we weren't getting together as a group as often as we should...that prompted us to start doing it again." Nurse practice $\mathrm{N}$

"there was nothing earth-shattering that they came up with... we were adopting a siege mentality... there was a lot of pressure... and perhaps getting together, talking....and developing more as a team...is the message that came from them...' GP partner 1 practice $\mathrm{K}$

"it's created good conversation in the practice... we talk more now...we were just doing the hamster wheel really." GP partner 2 practice $\mathrm{K}$

"it really has encouraged more open-ness within the surgery..." Nurse 1 practice $\mathrm{K}$

"...it was good for people to be able to say honestly how they felt about things." Administrator practice $\mathrm{K}$

"...there has been better communication from on high and that's working its way through..." Nurse practice $\mathrm{F}$

"...better access for the patients...because we've got some advanced nurse practitioners in..." Nurse practice $\mathrm{K}$

“...[the team] supported us all the way through the process of recruitment...actually recruiting [to a practice leadership role] but also the concept of having [a person in that role]...looking at the whole structure and our forward strategy...helped us to solidify what our vision was..." GP partner practice C

"To talk to somebody and have a chance to bounce your own ideas back and forth is positive in itself even without an action plan...in fact members of staff have come forward with ideas since [the Team] have come in and maybe it prompted that...just being asked sometimes prompts ideas..." GP partner practice G

"[the manager] did a whole report...and told us where our weaknesses are where we need to improve, which was a good thing because by the time the CQC inspectors came we had... achieved all the things." Practice manager practice $\mathrm{E}$ 
that staff were reporting these positive perceptions is in itself evidence of improved morale, and a variety of professional groups are represented, suggesting that changes were not only being perceived by those at managerial level (who had made the decision to work with the SCGP team).

There were perceptions in some practices that though some change had taken place, it was the beginning of a process and more input was needed.

One practice described a temporarily negative outcome in which the report produced by the SCGP team at the end of its scoping phase created some divisions between staff groups which contributed to two staff members leaving the practice; however, the overall perception of the outcome was that communication had improved as a result.

I think it caused a break-up, certainly, for a short period of time... Practice manager practice A

it helped to improve things because it helped to have a lot more open conversations...I think we've established a better structure. GP partner practice A

Two GPs (from different practices) expressed some anxiety about the provision of continuing support.

NHS England have now got to help us with a rescue plan...it's become more of a rescue plan than an action plan. GP partner practice $\mathrm{H}$

I do hope nobody gets rid of them before we're finished. It's a valuable asset really...we can see some light at the end of the tunnel but we're not out of the woods by any means. GP partner practice $\mathrm{K}$

\section{CMO configurations}

We present CMO configurations ${ }^{19}{ }^{20}$ relating to seven practices chosen to show a variety of different situations and practice needs. Among this group, there are practices with each of the following contexts (table 3):

- Practices which chose to approach the team for help;

- Practices which were approached by the team:

- Those who took up the offer of help,

- Those who did not take up the offer;

- A practice which had 'failed' a CQC inspection.

Practices are included from the first two groups identified above which had an initial negative reaction but which took up the offer of help and reported good experiences overall, practices in which the reaction stayed negative and further input was declined, practices in which there were mixed responses from staff, and practices where change was clearly attributed to the SCGP team.

Apart from the practice which was involved with the SCGP team because of a CQC inspection, these practices were initially engaged with the team in its early existence, which meant that there was sufficient time between the first and follow-up interviews for some change to take place in the practices and practice staff to be able to evaluate the impact of the team.

The other practices are not included either because it was considered that inclusion would not contribute anything more to the evaluation, or if data were incomplete because of timescales or practices' choices about participation in the evaluation.

\section{The programme specification}

The following programme specification was developed from the CMO analysis (see figure 2).

When practices are identified as performing poorly work with a well-functioning multidisciplinary team which has appropriate expertise (knowledge, experience and skills) to help them to identify areas and strategies for improvement and then support them to implement these strategies, some practices will accept and benefit from the engagement. For others, especially where they have not actively sought the help of such a team, acceptance is difficult due to negative perceptions including shame, and these practices are less likely to continue with engagement or perceive a value in it. However, practices which engage as a result of a CQC inspection are likely to view engagement positively. Tailoring the intervention to the specific needs of the practice is critically important. The principal positive mechanism for change is the expertise of members of the team. Practices may not engage in a linear manner, and outcomes may be delayed.

\section{DISCUSSION}

This evaluation has shown that when general practices engage with a team whose purpose is to support change, change can take place even in a short timescale. There are clear signs of the 'green shoots of recovery' in the practices manifested in better communication, morale and skill mix (table 2).

Using realist methodology, we have considered CMO configurations (table 3) to inform a programme specification. Mechanisms either belonged to the "resource"19 of the team or to the 'reasoning', 19 of the practice staff. While some mechanisms were predominantly positive or negative, the effects of others were contingent on factors in individual practices' contexts, such as the route to engagement with the SCGP team, influences of inspection and regulation, and the daily challenges experienced by the practices. The expertise of the SCGP team was consistently positive while the 'external view' provided by the SCGP team was variable and more likely to be positive when a practice had actively sought the input of the team; even then some individuals viewed it negatively early in their involvement.

In the current context of the NHS in England, there is an emphasis on inspection and regulation ${ }^{3-11}$ and negative feelings are known to arise in relation to this. ${ }^{11} 30$ Where there is inspection and judgement 


\section{Table 3 The CMO configurations}

\section{Practice CMO configurations}

$1 \quad$ Context. self-referral for management and leadership problems

Early negative reasoning mechanism: mistrust related to communication with the team, leading to a delay in further engagement

Positive reasoning mechanism: external view/corroboration

Positive resource mechanism: the expertise of the team's manager in recruitment

Outcomes: perceptions of a more appropriate skill mix within the clinical and managerial teams and better access to appointments for patients. Ongoing work with the SCGP team

2 Context. practice approached by the SCGP team as an outlier in NHS performance indicators. Problems with management and leadership

Positive resource mechanism: the SCGP team's manager, while the team as a unit was a negative mechanism due to disruption/divisions caused by the report

Negative reasoning mechanism: corroboration in that the practice perceived that they already knew what their development needs were and were addressing them

Outcome: perceptions that communication improved. The practice did not work with the SCGP team after the initial phase.

3 Context. self-referral re an anticipated CQC inspection. Concerns about the nursing team

Positive resource mechanisms: the specific expertise of the SCGP team's manager and nurse, the action planning and the clinical backfill

Positive reasoning mechanisms: better preparation for the CQC inspection (related to better function and workload management) and advocacy within the practice teams

Outcomes: effective recruitment, better workflow and a good result in the CQC inspection. Ongoing work with the SCGP team

$4 \quad$ Context. practice approached by the SCGP team as an outlier in NHS performance indicators. Problems with skill mix in the nursing and managerial teams, and workflow

Early negative reasoning mechanism: shame

Positive reasoning mechanism: corroboration

Positive resource mechanism: expertise and practical support of the SCGP team's manager Outcomes: better skill mix in the management and nursing teams, and better workflow. Ongoing work with the SCGP team Context. practice 'in special measures' after a CQC inspection with requirement for an action plan in a specific and short timescale. Management and leadership, deployment of clinical staff, and governance needed to be improved Positive resource mechanisms: the expertise of the team members and the action planning. The lead GP in the SCGP team was a specific resource for the lead GP in this practice working on the organisational aspects of his consultations.

Positive reasoning mechanisms: 'sustainability' (in that the practice thought its viability as a provider of general practice services would improve if it engaged with the SCGP team), and 'action planning' which would result in better function in terms of the CQC's requirement that they produce and implement an action plan Negative reasoning mechanisms: shame, mistrust and regulation/inspection.

Outcomes: increased morale of practice staff, more appointments for patients by means of recruitment and better skill mix, and 'better workflow'. Ongoing work with the SCGP team

6 Context. practice approached by the SCGP team. There were a number of areas for development which the practice staff knew about but were unable to address because of workload.

Positive reasoning mechanisms: external view/corroboration and development of better functioning practice team Positive resource mechanisms: multidisciplinary expertise. No negative resource or reasoning mechanisms identified in the early interviews, but engagement ceased before some of the leadership development was completed. Outcomes: staff perceptions of better communication, a more appropriate skill mix and more appointments for patients. Work with the SCGP team ceased after the report was produced.

Context. practice approached by the SCGP team as an outlier in NHS performance indicators. Problems with deployment and development of clinicians, and management and leadership Positive resource mechanisms: expertise of the SCGP team and lack of disruption

Positive reasoning mechanisms: corroboration and normalisation

Negative reasoning mechanism: "there wasn't anything they could offer to help us with." Outcome: increased morale as a direct result of external view mechanism. Work with the SCGP team ended after the report was produced.

$\mathrm{CMO}$, contexts, mechanisms and outcomes; CQC, Care Quality Commission; GP, general practitioner; SCGP, Supporting Change in General Practice; NHS, National Health Service.

against a standard, there is the possibility of failure to reach the standard. For this group of practices, the external standards which led to their engagement with the SCGP team were those of the $\mathrm{NHS}^{3-5}$ and the
CQC. ${ }^{8}$ The 'naming and shaming' which takes place in the NHS $^{10}{ }^{11}$ is a process involving humiliation ${ }^{31}$ and feelings of shame and anger may result, especially when there is a perceived risk of loss of public reputation and 


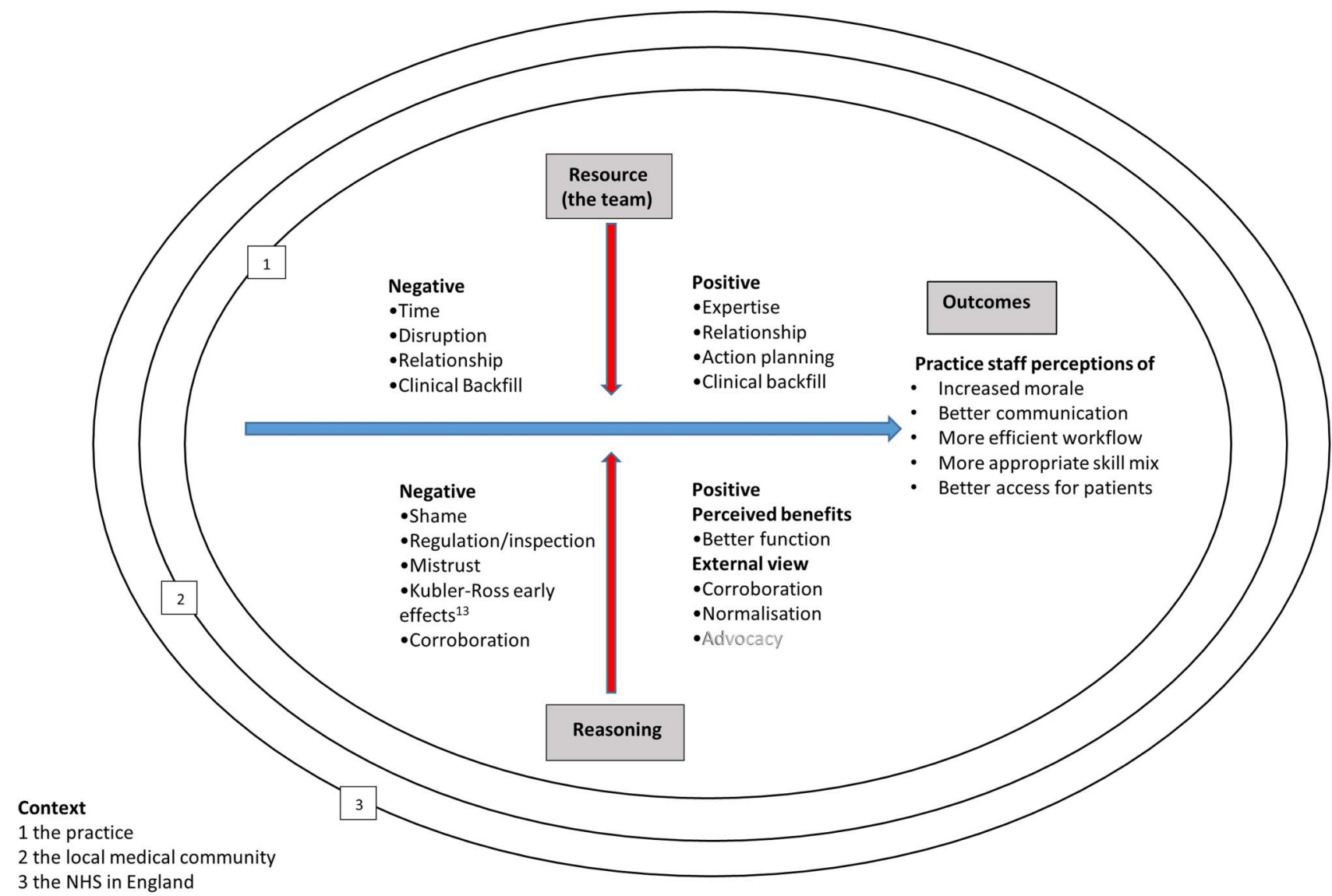

Figure 2 A summary of the contexts, mechanisms and outcomes. NHS, National Health Service.

'standing within a given social sphere'. ${ }^{32}$ The process of change itself, even when desired, also induces negative emotions ${ }^{25}$ which may be explained by the Kubler-Ross Change Curve; ${ }^{24}$ shock, anger and denial tend to be followed by acceptance and eventually more positive emotions. These negative reactions may have become focused on the SCGP team itself rather than on the need to change, which may have been the real cause of them, and they may have been responsible for the difficulty some practice staff had in engaging with the SCGP team. For some practices, a specific negative emotion was a disincentive for engagement with the team, particularly related to concerns about how engagement might be perceived in local medical communities. We interpreted and labelled this as 'shame', as it was related to the practices' perceptions that the SCGP team was for 'failing practices'. It is possible that being seen to be needing help also contributed to this. ${ }^{33}$ Both selfreferring and practices which had been approached by the team reported these negative reactions.

The usefulness of reasoning and resource mechanisms depended heavily on the quality of the relationships between practice staff and the team, dependent in their turn on skilled and sensitive communication in the contexts of the practices' reactions to their situations. There are examples in table 1 of perceptions of suboptimal communication which affected the effectiveness of the
SCGP team in promoting change, the negative mechanisms being 'mistrust' and 'relationships'.

For this group of practices, the issues which had led to their engagement with the team were very similar to those described by Rendel et al: ${ }^{18}$ low morale, leadership and management issues and staffing issues.

\section{Strengths and limitations}

A strength of this work was the use of a recognised and relevant research methodology. Though there has been a lack of agreement over what makes for a realist evaluation of high quality, the recently published reporting standards ${ }^{20}$ go some way towards addressing this, and these standards have been used to inform this work. We have described both the data collection and analysis and the care we took to ensure rigour in both. Though the numbers are small, all practices which engaged with the team in its first 2 years were involved in the evaluation. A range of practice staff was interviewed, not just those in acknowledged leadership roles. Some practices which did not engage with the team beyond the initial stage participated in the evaluation, which gave balance to the data.

There are limitations; 2 years is a short timescale in which to evaluate change, and review of the practices' progress in the future is likely to yield useful data. Some of the more negative emotions identified as having been generated by the need to change are difficult to discuss, 
and the researchers are aware that a deeper discussion would contribute much to the evaluation. Practices which did not engage at all with the team also declined to participate in the evaluation; the views of this important group of practices are therefore not represented. Those practices which had engaged with the SCGP team for reasons related to CQC inspections (which carry the ultimate sanctions of prosecution or closure ${ }^{8}$ ) are likely to be highly motivated to change. The study is embedded in the context of a highly inspected, highly regulated service: generalisability to less heavily managed systems cannot be assumed.

The evaluation team included two GPs who work in the same medical community as the SCGP team. This meant that they were exposed to the informal perceptions of others in that community regarding the team's work, however, neither worked in practices with which the team was involved, and both are experienced in the practice of reflexivity as part of qualitative research methodology. Though this is likely to have reduced the possibility of subjective bias, it is not possible to remove the effects of this completely.

\section{CONCLUSION}

In the current context of the English NHS, this support team has been effective in promoting change within practice teams via the mechanisms of an external view on their situations and shared expertise in their individual contexts of a need to improve. There were clear signs of 'green shoots of recovery' in that participants reported better morale, skill mix and communication within all of the practice teams. Nevertheless, practice staff may have negative reactions to such teams, related to perceptions of shame and feelings of mistrust arising from the current context of inspection and regulation in the NHS, which may impact on relationships with team members.

This study demonstrates that, to be successful, such interventions need to be carefully tailored and responsive to the practices' needs. Relationships between team members and practice staff are central to success and team members need to be sensitive to the multiple and, at times, conflicting drivers for practice engagement and change. Careful communication is essential but change can be achieved.

Acknowledgements The authors would like to acknowledge Dr Chris Harrison of Keele School of Medicine for his help as a critical friend on a late draft of this paper and Dr Geoff Wong of Oxford University for his advice on the use of Realist methods in evaluation.

Contributors The evaluation was jointly designed by MB and RKM and led by $M B$. The data were collected and analysed by MB and RB. MB wrote the first draft, while RB and RKM contributed to subsequent revisions. All authors approved the final draft.

Funding This work was commissioned and funded by NHS England, grant number IR00502.

Competing interests All authors have completed the ICMJE uniform disclosure form at http://www.icmje.org/coi_disclosure.pdf and declare that the work was funded by a grant paid by NHS England to Keele University. MB and $\mathrm{RB}$ received payment from Keele University for the work they did on the project. MB and RKM are general practitioners in practices from which NHS England commissions general medical services; however, since neither are GP principals, they are not involved in strategic or financial decision-making within the practices.

Provenance and peer review Not commissioned; externally peer reviewed.

Data sharing statement No additional data are available.

Open Access This is an Open Access article distributed in accordance with the Creative Commons Attribution Non Commercial (CC BY-NC 4.0) license, which permits others to distribute, remix, adapt, build upon this work noncommercially, and license their derivative works on different terms, provided the original work is properly cited and the use is non-commercial. See: http:// creativecommons.org/licenses/by-nc/4.0/

\section{REFERENCES}

1. Starfield B, Shi L, Macinko J. Contribution of primary care to health systems and health. Milbank Q 2005;83:457-502.

2. Campbell SM, Hann M, Hacker J, et al. Identifying predictors of high quality care in English general practice: observational study. BMJ 2001;323:784-7.

3. Quality and Outcomes Framework. Health and Social Care Information Centre. 2015. http://www.hscic.gov.uk/qof (accessed 28 2 2016).

4. NHS England. CCG Outcomes Indicator Set 2015/15-at a glance. http://www.england.nhs.uk/ccg-ois/ (accessed 52 2015).

5. Intelligent Monitoring NHS GP practices indicators and methodology. 2014. http://www.cqc.org.uk/sites/default/files/20141205\%20GP\% $201 \mathrm{M} \% 20$ Indicators\%20and\%20Methodology\%20Guidance.pdf (accessed 88 2016).

6. Lester H, Campbell S. Developing Quality and Outcomes Framework (QOF) indicators and the concept of 'QOF ability'. Qual Prim Care 2010;18:103-9.

7. Croker JE, Swancutt DR, Roberts MJ, et al. Factors affecting patients' trust and confidence in GPs: evidence from the English national GP patient survey. BMJ Open 2013;3:e002762. (accessed 22.8.2016).

8. The Care Quality Commission. Doctors/GPs. 2015. http://www.cqc. org.uk/content/doctorsgps (accessed 282 2016).

9. Blake A, Sparrow N, Field S. The CQC inspections: what they mean for general practice. Br J Gen Pract 2015;65:112-13.

10. Besley TJ, Bevan G, Burchardi KB. Naming and shaming: the impacts of different regimes on hospital waiting times in England and Wales. London School of Economics Research Online. 2009. http://eprints.Ise.ac.uk/33775/ (accessed 1308 2016).

11. Gerarda C. Something is profoundly wrong with the NHS today. BMJ Careers. 2014. http://careers.bmj.com/careers/advice/view-article. html?id=20018022 (accessed 1308 2016).

12. Lemieux-Charles L, McGuire W. What do we know about health care team effectiveness? A review of the literature. Med Care Res Rev 2006;63:263-300.

13. Aranzamendez G, James D, Toms R. Finding antecedents of psychological safety: a step towards quality improvement. Nurs Forum 2014;50:171-8.

14. Engels $Y$, van den Hombergh $P$, Mokkink $H$, et al. The effects of a team based continuous quality improvement intervention on the management of primary care: a randomized controlled trial. Br J Gen Pract 2006;56:781-7.

15. Kotecha J, Han $\mathrm{H}$, Green $\mathrm{M}$, et al. The role of practice facilitators in Ontario primary healthcare quality improvement. BMC Fam Pract 2015;16:93.

16. Kotecha J, Han $\mathrm{H}$, Green $\mathrm{M}$, et al. Influence of a quality improvement learning collaborative program on team functioning in primary healthcare. Fam Syst Health 2015;30:222-30.

17. Dean P, Farooqi A, McKinley RK. Quality improvement in general practice: the perspective of the healthcare team. Qual Prim Care 2004;12:201-7.

18. Rendel $\mathrm{S}$, Crawley H, Ballard T. CQC inspections: unintended consequences of being placed in special measures. $\mathrm{Br} J$ Gen Pract 2015;65:e640-1.

19. Pawson R, Tilley N. Realistic evaluation. London: Sage Publications, 1997.

20. Greenhalgh T, Wong G, Jagosh J, et al. Protocol-the RAMESES ॥ study: developing guidance and reporting standards for realist evaluation. BMJ Open 2015;5:008567.

21. NHS Employers Changes to QoF. 2015. http://www.nhsemployers. org/your-workforce/primary-care-contacts/general-medical-services/ 
quality-and-outcomes-framework/changes-to-qof-2015-16 (accessed 52 2016).

22. Intelligent Monitoring of GP practices- data update. 2014. http://www. cqc.org.uk/content/intelligent-monitoring-gp-practices-data-update (accessed 88 2016)

23. Anderson NR, West MA. Measuring climate for work innovation: development and validation of the team climate inventory. J Organ Behav 1998;19:235-58.

24. Kubler-Ross E. On death and dying. London: Routledge, 1969.

25. Kuipers BS, Higgs M, Kickert W, et al. The management of change in public organizations: a literature review. Public Adm 2013;92:1-20.

26. Health Research Authority. Research Decision Tool. http://www. hra-decisiontools.org.uk/research/ (accessed 103 2014).

27. Department for the Environment. Food and Rural Affairs (UK Government). 2016. Defining rurality. https://www.gov.uk/ government/uploads/system/uploads/attachment_data/file/495639/ Defining rural areas Jan_2016 .pdf (accessed 102 2016).

28. Department of Health. Health Information: Common Measures of Health Service Provision and Usage. 2012. http://www.

healthknowledge.org.uk/e-learning/health-information (accessed 15 5 15).

29. The King's Fund. Exploring CQC's well-led domain. 2014. http:// www.kingsfund.org.uk/publications/exploring-cqcs-well-led-domain (accessed 2011 2015)

30. Limb M. GPs call for an end to CQC inspections. BMJ 2016;352:i636.

31. Deonna JA, Rodogno R, Teroni F. In defense of shame: the faces of an emotion. New York: Oxford University Press, 2012:156-63.

32. Deonna JA, Rodogno R, Teroni F. In defense of shame: the faces of an emotion. New York: Oxford University Press, 2012:30.

33. Mollon P. Shame and Jealousy, the Hidden Turmoils. London: Karnac, 2002:125. 